Piette, Albert. 2014. Contre le relationnisme. Lettre aux anthropologues. Lormont:

Editions le Bord de l'Eau (Collection: Perspectives anthropologiques). 95 pp. Pb.: 10€. ISBN: 9782356873019

As its title clearly summarizes, this small book, written in the form of a letter addressed to fellow anthropologists, is conceived as a critique to a dominant line of thought in anthropology that privileges analysis in terms of relation, which the author denominates 'relationnism'. Albert Piette considers that anthropology should focus instead on the existence of human beings as a singular, evolving and lived reality. This perspective goes far beyond an attention to relation. For Piette, humans are more than beings in contact with other beings and, especially, more than a set of relations that are actualized at a particular moment in time.

Piette starts by critically reviewing differentdefinitions of relation by influential authors, namely Goffman, Lévi-Strauss and Bourdieu. He identifies three conceptions - relation as interaction, the individual as relation and the individual as related to a system — that in his view equally fail to account for the entire 'volume' of each being. The author directly targets Latour, who, in his opinion, has posited more than others the primacy of the relational, by conceiving the individual only in function of the network in which s/he is situated. Piette does not however deny the importance of relations. He aims instead to critique a perspective that focuses only on relations and on the in-between. According to him, recent considerations on ethnography in terms of social encounter and relational play stem from this overarching 'relationnist' perspective.

Starting from this critique, Piette develops his own anthropological perspective. Leaving the study of society and culture, as synthesized wholes, to sociologists and 
ethnologists, he advocates for an existential anthropology: an empiricist and realist science of human beings, which focuses on individuals as living singularities. The method necessary to carrying out such an anthropology he calls 'phenomenography'. This consists in the micro-observation of an individual in the continuity of his/her existence and entails a sustained attention for the modalities and ever-changing intensities and nuances of his/her presence and absence in the course of each action. This method of 'shadowing'- a research technique that involves the researcher closely following someone over an extended period of time - includes the description of 'minor gestures', which may have nothing to do with the main stake of the on-going situation. When following an individual, the observer should also take into account other presences that enter into the latter's existence such as animals, divinities or the State, as well as culture and interactions with other individuals. Relations hence return to the researcher's attention by means of the individual and are situated, so as to no longer be reduced to an empty in-between.

In the last ten pages of his book Piette suggests possible developments of this existential anthropology. According to him such an approach, far from being apolitical, could become the basis of an anthropological pedagogy by recalling to researchers, in the face of dehumanizing extremist tendencies, the duty to remember every human's uniqueness at all times. It could moreover provide further insight into basic features of human modalities of existence. In a hypothetical digression, the author suggests that a defining characteristic of Homo Sapiens is its capacity of 'cognitive relaxing', whose origin he situates in the representation of an afterlife.

Piette's book offers a highly innovative view and a daring proposition for tackling the debated issue of defining anthropology's specificity. In my view as a social anthropologist, this book is also useful within the framework of the current trends in the 
discipline, notwithstanding the author's criticism of the latter. In contemporary social anthropology, convincing efforts have been made to avoid generalizing representations of people through reified notions of culture and society. Ethnographic accounts have also moved beyond the classical injunction to adopt 'the' indigenous point of view, in order to account for plural perspectives. Piette offers a radical method for advancing this endeavour: by sticking closely to the observed individual, his phenomenography aims to create realistic portrayals of humans as complex living beings who are never completely determined by structural social features.

However, the current anti-objectivist commitment of social anthropologists is lacking in Piette's work. He does not explicitly tackle the issue of subjectivity and appears to suggest that the observer, by meticulously applying their method, can somehow access 'the true reality' of the individual under study. In his attack on relationnism, Piette runs the risk of further reproducing a Western-biased view of individuals as bounded and autonomous beings. The author also puts forward quite generalizing ideas about the specificity of human beings as a clear-cut difference from animal species and Neanderthals. In this regard, I contend, he appears to disregard the precious contributions of those scholars associated with the 'ontological turn' whom he so clearly critiques.

\section{CARINE PLANCKE}

